Reaching for the (Product) Stars:

Measuring Recognition and Approach Speed to Get Insights into Consumer Choice

\author{
Oliver Genschow \\ University of Mannheim, Germany \\ Arnd Florack \\ University of Vienna, Austria \\ Vikram S. Chib \\ California Institute of Technology, CA, USA \\ Shinsuke Shimojo \\ California Institute of Technology, CA, USA \\ Martin Scarabis \\ decode Marketingberatung GmbH, Germany \\ Michaela Wänke \\ University of Mannheim, Germany
}

\begin{abstract}
Author Note
Oliver Genschow, Department of Consumer and Economic Psychology, University of Mannheim, Germany; Arnd Florack, University of Vienna, Austria; Vikram S. Chib, Division of Biology, Computation and Neural Systems, California Institute of Technology, CA; Shinsuke Shimojo, Division of Biology, Computation and Neural Systems, California Institute of Technology, CA; Martin Scarabis, decode Marketingberatung GmbH, Germany; Michaela Wänke, Department of Consumer and Economic Psychology, University of Mannheim, Germany.
\end{abstract}


The research reported in this article was supported by a grant from the German Research Foundation to the second author (FL 365/3- 1), and a grant from the decode Marketingberatung $\mathrm{GmbH}$ to the first and second author.

Correspondence concerning this article should be addressed to Oliver Genschow, Department of Consumer and Economic Psychology, Parkring 47, 68159 Mannheim, Germany, Germany.E-Mail: ogenscho@mail.uni-mannheim.de. 


\begin{abstract}
In three studies, an easy to apply and short response time task that is able to distinguish between recognition and approach speed was applied. Individuals recognized and approached distinctly positive stimuli faster than distinctly negative stimuli (Pilot Study). But, approach movement time was a better predictor of consumer choice and willingness to pay than recognition time (Study 1) when the choice options differed less distinctively in valence. Also, the approach movement time was a better predictor of consumer choice than self-reports when the choice was made with an affective compared to a cognitive focus (Study 2). Moreover, approach movement time, but not recognition time, correlated with different measures of implicit preferences, such as the IAT and an affective priming task. Implications of the use of this task in applied settings are discussed.
\end{abstract}


Reaching for the (Product) Stars: Measuring Recognition and Approach Speed to Get Insights into Consumer Choice

Research has shown that consumers make many of their decisions spontaneously at the point of purchase and engage in very little purchase deliberation (e.g., Abratt \& Goodey, 1990; Hoyer, 1984; Puri, 1996; Strack, Werth, \& Deutsch, 2006). A classic technique that has been applied in market research for decades to simulate such decisions is the swift-selection platform (e.g., Gutjahr, 1974; Jaspert, 1963; Salcher, 1995; Spiegel, 1970). Using this technique, a market researcher places a selection of product alternatives in a box and hides them behind a curtain. She or he then draws the curtain, and participants have to quickly select a product they like. It is assumed that consumers are faster at selecting a product the more positive and stronger their attitudes are, or, in other words, the stronger their behavioral approach predispositions toward the product are.

Swift-selection platforms have been used not only in applied market research, but also in basic research. For example, Fazio, Powell, and Williams (1989) applied a similar paradigm to examine the role of attitude accessibility in spontaneous decisions. They arranged 10 different products in two rows of five on a table and covered them with a tablecloth. At the appropriate time, the experimenter removed the tablecloth and told the subjects to choose five of the products.

Although such swift-selection procedures provide insight into behavioral approach predispositions toward specific objects, there are at least three disadvantages to their use. First, they require cumbersome testing because the experimenter has to carefully arrange the products and operate the visual screen. Second, the procedure provides limited data. Because participants do not respond to every single product, but select just a few out of many, the researcher is not able to assess approach predispositions toward all products of interest. Third, 
and most important, conventional swift-selection platforms do not distinguish between recognition and approach movement times, but rather lump these two parameters together.

In this paper, we argue that it is important to distinguish between recognition and approach times and present a technique that provides the ability to differentiate easily between these two parameters. Additionally, the objective of the present paper was to develop a response time task to measure behavioral approach speed that can be easily applied in market research and allows measuring in mass testing sessions as well as in web-based studies. It is important to note, however, that the presented technique was not designed to distinguish between no action and avoidance, because avoidance responses are not likely in consumer choice contexts where products vary in positivity and where disgusting or threatening objects are rare.

\section{Recognition and Approach}

Individuals are often faster in consciously recognizing positive compared to negative information (for an overview, see Unkelbach, Fiedler, Bayer, Stegmüller, \& Danner, 2008). Bargh, Chaiken, Govender, and Pratto (1992), for example, examined the amount of time individuals needed to evaluate positive and negative attitude objects. They found that positive attitude objects were evaluated more quickly than negative attitude objects. Indeed, the fact that positive information is on average more similar to other positive information than negative information is to other negative information (Unkelbach et al., 2008) facilitates the recognition of positive (e.g., flowers) compared to negative objects (e.g., insects). Moreover, positive objects often define the norm, whereas negative objects are perceived as deviations from the norm, and it is plausible that deviations from a norm are more difficult to recognize.

While existing evidence implies that faster recognition times can be expected for the recognition of positive objects than for the recognition of negative objects, the same holds for approach movements, which were shown to be faster for approaching positive compared to 
negative objects (e.g., Brendl, Markman, \& Messner, 2005; Chen \& Bargh, 1999; De

Houwer, Crombez, Baeyens, \& Hermans 2001; Krieglmeyer \& Deutsch, 2010; Van Dantzig, Pecher, \& Zwaan, 2008). Hence, we formulated the following hypothesis:

H1: Overall, recognition and approach times are faster for distinctly positive (e.g., flowers) than for distinctly negative objects (e.g., insects).

Whereas it is reasonable to assume that recognition and approach times are highly correlated when recognition and approach times for positive compared to negative objects are measured, the link between recognition and approach is less clear when the objects differ less distinctly in valence. Indeed, many attitude objects such as different kinds of snacks or beverages are not considered to be positive or negative. Such objects differ more in degrees of positivity, and preferences for these objects differ across individuals. Because the speed advantage in recognition time of positive over negative objects is mainly due to a higher density of positive objects, we assume that within categories that differ less in valence and density, recognition time is less likely to be correlated with preferences, whereas approach movement time should still be correlated with preferences for such objects.

Hot beverages or snacks are good examples of categories that include items that differ only gradually in valence and are differently evaluated by different individuals. For such categories, approach movement times should be more strongly linked to preferences than recognition times. Moreover, based on studies showing that the conceptual similarity of a measure to a behavior increases predictions of behavior (Ajzen \& Fishbein, 1977; Zanna, Olson, \& Fazio, 1980), we assumed that approach movements better depict choice than recognition. For instance, a consumer who is used to drinking tea every day may be as fast as a coffee drinker in recognizing the well-known logo of the Starbucks Coffee House even if she or he never goes there. However, a coffee drinker should be faster in approaching his favored coffee than a tea drinker would do, simply because approaching the coffee is the 
default response for the coffee drinker, but not for the tea drinker. Based on this reasoning, we formulated the following hypotheses:

$\mathrm{H} 2$ : When predicting consumer behavior within categories that differ less extremely in valence (e.g., hot beverages or snacks), approach time is a better predictor of choice than recognition time.

While recognition can lead to approach, no action, or avoidance, approach is a key component of the behavioral program elicited when consumers select a preferred product. Therefore, we assume that approach time taps automatic preferences more than recognition time, and, hence, should be more strongly correlated with other implicit measures of preferences such as the Implicit Association Test (IAT; Greenwald, McGhee, \& Schwartz, 1998) or affective priming (Fazio, Sanbonmatsu, Powell, \& Kardes, 1986).

H3: When predicting consumer behavior within categories that differ less extremely in valence (e.g., hot beverages or snacks), approach time, but not recognition time, is correlated with measures of implicit preferences.

Finally, we hypothesized that in certain contexts approach time is a better predictor of choice than self-report measures. If we think about applying a measure that could potentially replace the swift-selection platform in marketing research, it should add predictive power when considered in addition to self-report measures. Previous research has shown that explicitly measured preferences are of particular importance for the prediction of deliberate behavior and reasoned action. By contrast, research has shown that implicitly measured attitudes are better predictors of more impulsive and affect-driven behavior (Florack, Friese, \& Scarabis, 2010; Friese, Hofmann, \& Wänke, 2008; Friese, Hofmann, \& Wänke, 2009;

Friese, Wänke, \& Plessner, 2006; Hofmann, Gschwendner, Nosek, \& Schmitt, 2005). Accordingly, individuals should be more likely to rely on approach or avoidance impulses when they focus predominantly on affect than when they reflect on a decision. We therefore 
hypothesized that approach time (but not recognition time) is a better predictor of consumer choice than self-report measures when participants rely on their affective responses than when they think about reasons for their choices.

H4: Within categories that differ less extremely in valence such as consumer goods (e.g., hot beverages or snacks), approach time is a better predictor of consumer choice than self-report measures when individuals rely on their affective responses than when they think about reasons for their choice.

We are not aware of any research that has tested these hypotheses while applying a single measure to distinguish approach from recognition times. However, a few researchers have directly measured approach movements to gain insight into individuals' attitudes or evaluative predispositions toward objects (e.g., Brendl et al., 2005; Chen \& Bargh, 1999; De Houwer et al., 2001; Solarz, 1960). Because the measure we applied in the present studies refers directly to these methods, we provide a short overview of existing research in this area.

\section{Existing Measures of Approach Predispositions}

During the last decade, different response time measures of approach predispositions have been applied (Brendl et al., 2005; Chen \& Bargh, 1999; De Houwer et al., 2001; Krieglmeyer \& Deutsch, 2010; Van Dantzig et al., 2008). Chen and Bargh (1999), for instance, presented positive and negative pictures on a computer screen and asked participants to respond by moving a lever. In one phase of the experiment, participants were instructed to push the lever forward as quickly as possible when they judged the word to be "good," and to pull the lever back when they judged the word to be "bad." In another phase of the experiment, participants were given the opposite instructions: to pull the lever if the word was positive in meaning, and to push the lever if the word had negative connotations. The authors hypothesized that positive evaluations would produce immediate approach movements, and negative evaluations would produce immediate avoidance movements. The results showed 
that participants were faster at responding to negative stimuli when pushing rather than pulling the lever, but were faster at responding to positive stimuli when pulling rather than pushing the lever. Brendl et al. (2005) introduced a slightly different technique to measure individuals' approach and avoidance predispositions toward an object. In their studies, they presented the participant's name in the middle of a computer screen, and positive and negative stimuli appeared randomly beside the name. They instructed participants to move the presented stimuli with a joystick as quickly as possible toward their name if they considered the stimuli to be positive, and away from their name if they considered them to be negative. Subsequently, participants saw the same set of stimuli with the opposite instructions, to move positive stimuli away from their name and negative stimuli toward it. The results showed that participants moved the joystick more quickly toward than away from their name when they saw positive stimuli, but moved it more quickly away from than toward their name when they saw negative stimuli.

Recently, van Dantzig et al. (2008) simulated a movement of presented stimuli toward or away from the participants after participants executed a forward or backward movement. This study as well as other studies showed that it is not the movement per se, but its purpose that defines the movement as approach or avoidance (cf. Eder \& Rothermund, 2008; Hofsten \& Rönnqvist, 1988; Morange \& Bloch, 1996; Seibt, Neumann, Nussinson, \& Strack, 2008). A forward or a backward movement can mean approach when it leads to an increase in the size of an object on the screen or avoidance when it leads to a decrease in the size of an object on the screen.

All of the mentioned procedures nicely simulate actual approach and avoidance behaviors of the participants. However these tasks do not differentiate between recognition and approach movement speed, but rather lump these responses together. In the joystick tasks (e.g., Brendl et al., 2005; Chen \& Bargh, 1999), for example, the time between the appearance 
of a stimulus and the response of the joystick was measured, but not the speed of the movement from a point A to some point B. One exception is a task by Bamford and Ward (2008). This task is able to measure the speed of a movement separately from recognition speed. However, this measure has not been applied to study whether recognition and movement times predict any kind of behavior. Moreover, it is based on touchscreen technology, which requires participants to have some experience with touchscreens and records responses of participants with lower reliability than a keyboard.

With these concerns in mind, we constructed the recognition and behavioral approach task (RaBAT) that researchers can easily apply in consumer research. The objective of the RaBAT is to measure automatically activated approach tendencies while at the same time distinguishing recognition speed and approach movement speed.

\section{The Recognition and Behavioral Approach Task (RaBAT)}

Figure 1 illustrates the procedure of the Recognition and Behavioral Approach Task (RaBAT). Participants working on the RaBAT sit in front of a computer screen and are instructed to hold down the space bar with their right forefinger if they are right-handed, or with their left forefinger if they are left-handed. When participants press the space bar, the screen becomes white for a randomly selected time $(500-2,000 \mathrm{~ms})$. Then a picture appears on the screen. As soon as the participants recognize the picture, they have to release the space bar and press a key closer to the screen (i.e., the Z key on German/Swiss key boards; the Y key on American keyboards) with the same finger. After participants complete this movement, they have to return to the space bar; when they press the space bar, the screen becomes white again. The entire procedure repeats until every stimulus is presented. As mentioned above, the movement toward the stimulus may represent approach or avoidance (e.g., Eder \& Rothermund, 2008; Seibt et al., 2008; van Dantzig et al., 2008). In the RaBAT, pressing of the $\mathrm{Z}(\mathrm{Y})$ key elicits a virtual movement of the picture toward the participants and thereby ensures 
that the movement is associated with approach. In detail, the pictures become $25 \%$ bigger and are then presented for 1,000 ms after participants press the target key (cf. van Dantzig et al., 2008).

The RaBAT certainly has many advantages compared to other measures. Probably, the key advantage of the RaBAT is its ability to differentiate between the approach movement time and the recognition time of an object. The recognition time is defined as the time between the appearance of the picture and release of the space bar. The approach movement time is defined as the time participants need between releasing the space bar and pressing the Z (Y) key. A second advantage of the RaBAT concerns its flexibility on testing different kinds of stimuli. While other measures such as the IAT (Greenwald et al., 1998) are limited to two categories, the RaBAT is able to study responses to many groups and subgroups of items. A third advantage of the RaBAT lies in its simple and quick application. The version presented here needs few trials, participants respond toward every stimuli in the same manner and since no joystick or other additional equipment is needed, the RaBAT can be applied for mass testing in web-based settings. Moreover, because individuals working on the RaBAT respond in the same manner toward every stimulus, criticism that has been focused on double categorization tasks (e.g., positive vs, negative and target 1 vs, target 2), which is an integral component of the IAT and other implicit measures (Fiedler, Messner, \& Bluemke, 2006), does not apply to the RaBAT.

\section{Overview of Research}

In three studies, we tested our hypotheses and the ability of the RaBAT to measure recognition and approach times. Before testing our primary hypotheses concerning the prediction of consumer behavior and preferences from responses on the RaBAT, it was first necessary to show the RaBAT's ability to replicate basic findings concerning the relationships between valence and approach speed as well as valance and recognition speed. Namely, 
previous work suggests that approach time (Brendl et al., 2005; Chen \& Bargh, 1999; De

Houwer et al., 2001; Krieglmeyer \& Deutsch, 2010; Van Dantzig et al., 2008) and recognition time (for an overview, see Unkelbach et al., 2008) should be faster for positively (versus negatively) valenced stimuli. If the RaBAT is a valid task to measure approach movement times and recognition speed, then it should be able to reproduce these findings. Thus, in a Pilot Study, we aimed to replicate these findings by testing whether recognition time and approach movement time measured with the RaBAT would be faster when positive objects compared to negative objects were presented.

In Studies 1 and 2, we used stimuli that did not differ in valence and tested the correlations of recognition and approach movement times with consumer behavior. We assumed that approach movement time is a better predictor of consumer preferences, willingness to pay, and implicit preferences. Study 2 furthermore examined whether approach movement time measured with the RaBAT enhances the prediction of choice compared to self-report measures when participants focus on their affect during choice.

\section{Pilot Study}

In the Pilot Study, we used the RaBAT to measure recognition speed and behavioral approach predispositions according to two concepts, each with a distinctly positive or negative valence: flowers and insects. As a first step toward validating the measure, we chose these two concepts because they differ clearly in valence. With respect to approach movement time, we hypothesized that participants would move their finger from the space bar to the $\mathrm{Z}(\mathrm{Y})$ key faster when seeing a picture of a flower than when seeing a picture of an insect on the computer screen (cf. Hypothesis 1). According to the recognition time, we assumed in line with previous research, which has shown that individuals recognize positive stimuli more quickly than negative stimuli when responses require conscious recognition (for an overview, 
see Unkelbach et al., 2008), that participants would be faster at releasing the space bar when seeing flowers compared to insects (cf. Hypothesis 1).

\section{Method}

Participants. Twenty-seven students ( 6 men and 21 women) from the local university were recruited in exchange for partial course credit and were tested in groups of up to four persons. The ages of participants ranged from 19 to 43 with a mean age of $24.89(S D=4.83)$. For one participant, no response time data were recorded because of a computer error. A further participant indicated that she did not follow the instructions. Both participants were excluded from the analyses.

Materials and Apparatus. As target concepts, we used 10 pictures of flowers (e.g., daisy, lily, poppy) representing positive stimuli, and 10 pictures of insects (e.g., mosquito, beetle, cockroach) representing negative stimuli. Similar stimuli have been used in previous research on implicit attitudes (e.g., Greenwald et al., 1998). All pictures had a size of $685 \mathrm{x}$ 549 pixels. In addition to these target stimuli, we used 20 pictures of everyday objects (e.g., comb, salad bowl, drill) as stimuli in a practice block.

We conducted the experiment on Apple Macintosh (Intel Core 2 Duo processor) desktop computers with Windows XP as the system software. Participants viewed the screen from a distance of approximately $55 \mathrm{~cm}$ and responded on a Swiss keyboard. We conducted the experiment in a laboratory using Mozilla Firefox 5.0 as the browser.

Measures. Recognition and Behavioral Approach Task. The RaBAT contained a practice block and a trial block. In both blocks, participants completed the trials as described above. However, the instructions varied slightly between the practice block and the trial block. In the trial block, we instructed participants to react as soon as they recognized the pictures as either flowers or insects. This means they did not have to recognize specific flowers and insects, but merely the category of the pictures. In the practice block, we 
instructed participants to press the $\mathrm{Z}$ key as soon as they recognized the exact type of stimuli (e.g., salad bowl). As it is typical for response time measures (cf. Fazio, 1990), we discarded all latencies that deviated more than 2 SD from the average and then log-transformed all response latencies to prepare the data for analyses. This approach was used for all studies in this paper. Afterwards, we computed mean recognition times (time from presentation of the picture until release of the space bar) as well as mean approach movement times (time between releasing the space bar and pressing the target key) for flower and insect pictures. All analyses were computed with the log-transformed latencies. However, to facilitate interpretation, we report the means of the untransformed latencies.

Evaluation of the pictures. After completing the RaBAT, participants evaluated every picture they saw in the trial block. On a 9-point scale ranging from 1 (not at all) to 9 (absolutely), they indicated the degree to which they agreed with the following statements: "This picture is positive" and "This picture is negative." We then averaged the ratings of all flower pictures on the positive (Cronbach's $\alpha=.76$ ) and on the negative scales (Cronbach's $\alpha$ $=.85$ ), as well as the ratings of all insect pictures on the positive (Cronbach's $\alpha=.79$ ) and the negative scales (Cronbach's $\alpha=.76$ ).

\section{Results}

Evaluation of flower and insect pictures. As expected, participants evaluated flower pictures $(M=7.54, S D=.85)$ more positively than insect pictures $(M=3.58, S D=1.19), t(24)$ $=13.21, p<.001, d=4.11$. Also, they evaluated flower pictures less negatively $(M=1.74, S D$ $=.78)$ than insect pictures $(M=5.86, S D=1.27), t(24)=-13.11, p<.001, d=3.91$.

Main analyses. We expected faster approach movement times toward flower than toward insect pictures, and faster recognition times of flower than of insect pictures. Congruent with our hypothesis, participants' approach movements were faster for flower pictures $(M=247.37 \mathrm{~ms}, S D=55.70)$ than for insect pictures $(M=261.03 \mathrm{~ms}, S D=74.27)$, 
$t(24)=2.89, p=.008, d=0.16$. Also in line with the hypothesis, the mean recognition time was faster for flower pictures $(M=458.98 \mathrm{~ms}, S D=87.13)$ than for insect pictures $(M=$ $481.85 \mathrm{~ms}, S D=99.42), t(24)=3.21, p=.004, d=0.20$.

\section{Discussion}

In the Pilot Study, recognition and approach movement times measured with the RaBAT were faster for flower pictures, a distinctly positive concept, than for insect pictures, a distinctly negative concept. These results are in line with previous research on the speed needed to process positive and negative information (e.g., Unkelbach et al., 2008) and previous research on behavioral approach predispositions (e.g., Chen \& Bargh, 1999). They furthermore show that recognition speed and behavioral approach movements can be adequately measured with the RaBAT.

\section{Study 1}

Although the Pilot Study has shown that the recognition time is faster for positive compared to negative stimuli, it is not clear whether recognition time is sensitive enough to capture differences in degrees of favorableness as it is typical for choice options in consumer contexts. Since recognition time is strongly driven by the density of the categories, and therefore by distinct differences in valence, and approach movements are more closely linked to consumer choice, we assumed that individual differences in approach movement time would better predict consumer preferences than individual differences in recognition time (cf. Hypothesis 2).

In Study 1, we therefore tested whether recognition and approach movement times toward coffee and tea pictures could predict consumer choice, willingness to pay, and explicit preferences for the respective category. In addition, we examined the correlations of recognition and approach movement times with an Implicit Association Test (IAT;

Greenwald et al., 1998). The IAT has been previously applied in consumer research to assess 
implicit consumer attitudes and consumer brand relations (e.g., Brunel, Tietje, \& Greenwald, 2004; Dimofte, \& Johansson, 2009; Dimofte, \& Yalch, 2007; Horcajo, Briñol, \& Petty, 2010;

Maison, Greenwald, \& Bruin, 2004) and has been repeatedly shown to predict spontaneous or affect-driven consumer behavior (for reviews, see Dimofte, 2010; Friese et al., 2009;

Greenwald, Poehlman, Uhlmann, \& Banji, 2009). Hence, we expected at least moderate correlations of the RaBAT approach movement times with the IAT score (cf. Hypothesis 3).

\section{Method}

Design and participants. We recruited participants via a mass emailing for market research about hot beverages. Forty participants ( 19 men and 21 women) accepted our invitation and participated in the study. The ages of participants ranged from 16 to 58 years with a mean age of $32.75(S D=12.37)$. We excluded one participant from data analyses because of a RaBAT approach movement score that was more than 2 standard deviations above the sample mean.

Procedure. Participants were tested in groups of up to four persons. When they entered the laboratory, the experimenter greeted and thanked them for taking part in the experiment. The participants were then informed that the experiment consisted of several parts, including two response time measures and a questionnaire. After signing a statement of agreement, participants first completed the RaBAT (approximately 1.5 minutes), and then the IAT (approximately 4 minutes). Next, participants filled out a questionnaire about consumer behavior on the computer (approximately 3.5 minutes). After data collection had been completed, they received 25 Swiss Francs (approximately \$24 US, or $19 €$ ) in exchange for their participation.

Materials and apparatus. For the RaBAT and the IAT, we chose 10 pictures for coffee and 10 for tea (see Figure 2 for sample stimuli). For each category, the same variation of background and depicted cups and pots was shown. Only the content of the depicted 
containers differed, showing either coffee or tea. All pictures had a size of $685 \times 549$ pixels. We conducted the experiment on IBM-compatible ( $3000+$ processor) desktop computers with Windows XP as the system software. Participants viewed the screen from a distance of approximately $55 \mathrm{~cm}$ and provided responses on a Swiss keyboard.

Measures. Recognition and Behavioral Approach Task. Except for the target pictures, the procedure of the RaBAT was exactly the same as in the Pilot Study. For data analyses, we log-transformed all latencies and computed means for recognition of coffee pictures and of tea pictures, as well as for the approach movements toward coffee pictures and toward tea pictures. We then subtracted the mean approach movement time toward coffee pictures from the mean approach movement time toward tea pictures. High values indicate stronger relative approach tendencies toward coffee compared to tea pictures. Likewise, we computed the recognition difference with higher values indicating faster recognition of coffee pictures compared to tea pictures.

$\boldsymbol{I A T}$. We applied an IAT (Greenwald et al., 1998) with the target categories coffee and tea and the attribute categories pleasant and unpleasant. In the IAT, we used positive (e.g., sunset, sea, baby) and negative pictures (e.g., gun, bear, shark) from the International Affective Picture System (IAPS; Lang, Bradley, \& Cuthbert, 2005) as evaluative stimuli. Pictures of tea and coffee (see above) represented the target categories. Each combined block consisted of 40 trials. In one combined block, participants sorted positive (negative) pictures and pictures depicting coffee (tea) with one response key. In the other combined block, this assignment was reversed such that positive (negative) stimuli and tea (coffee) stimuli shared one response key. The order of the combined blocks varied between participants. Half of the participants first completed the positive-coffee/negative-tea block and then the positivetea/negative-coffee block; the other half of the participants first completed the positivetea/negative-coffee block and then the positive-coffee/negative-tea block. We calculated the 
IAT effect using the d-measure proposed by Greenwald, Nosek, and Banaji (2003) such that positive values indicate stronger implicit preferences for coffee compared with tea.

Choice. In two scenarios, we asked participants to choose between coffee and tea. In the first scenario, participants had to imagine the following situation: "Imagine you are doing bulk buying for your personal needs. Altogether, you buy 10 packages of coffee and tea. How many of these packages would be coffee and how many would be tea?" In the second scenario, we asked participants to consider the following situation: "Imagine you are buying a coffee- and tea-machine. Using this machine, people can prepare coffee as well as tea. There are 10 packages of capsules included in the purchase. You now have to decide how many of these packages will include coffee and how many will include tea." Answers from both scenarios were coded on an 11-point scale ranging from 1 (10 packages of tea and no packages of coffee) to 11 (10 packages of coffee and no packages of tea) and then averaged into a single scale such that high values indicate choosing more coffee than tea (Cronbach's $\alpha$ $=.89)$.

Willingness to pay. We asked participants to indicate the maximum price they would be willing to pay for a cup of coffee and for a cup of tea in a Swiss restaurant. We then subtracted the price for tea from the price for coffee. High values indicate that participants are willing to pay more for a cup of coffee than for a cup of tea.

Relative consumption preference. Participants indicated on a 9-point scale ranging from 1 (not at all) to 9 (very much) the degree to which they agreed with the following coffee and tea statements: "I am a coffee fan"; "I am a tea fan"; "I consider myself to be a coffee drinker"; "I consider myself to be a tea drinker"; "If I had to decide between coffee and tea, I would choose coffee"; "If I had to decide between coffee and tea, I would choose tea"; "During a year, I drink more coffee than tea"; "During a year, I drink more tea than coffee"; "In general, I prefer coffee over tea"; and "In general, I prefer tea over coffee." All self- 
reported preferences for coffee (Cronbach's $\alpha=.97$ ) and for tea (Cronbach's $\alpha=.95$ ) were summed into single scales. Next, we subtracted the score for tea preference from the score for coffee preference to establish a relative consumption preference measure. High values indicate a preference for coffee over tea.

\section{Results}

To test our hypotheses, we first examined the predictive validity of difference scores, that is, the difference between approaching tea and coffee pictures and the difference between recognizing tea and coffee pictures. We used difference scores in the first step because of two main reasons. First, response times are affected by many different variables like cognitive abilities and vigilance that are not related to differences in approach tendencies. Computing a difference score between two response time variables eliminates variance that is related to such noise. This is also the reason why difference scores are standard when response times are examined as predictors. For instance, the Implicit Association Test (IAT; e.g., Greenwald et al., 2003), affective priming tasks (e.g., Spruyt, Hermans, De Houwer, Vandekerckhove, \& Eelen, 2007), the Extrinsic Affective Simon Task (EAST; e.g., De Houwer, 2003), approachavoidance tasks (e.g., Hofmann, Friese, \& Gschwendner, 2009) and many other measures are based on difference scores. Second, consumer choice is often a choice between alternatives. In these cases, it is not a single approach score, but the relative score that is of importance. However, it is important to note that difference scores are limited in interpretation because they are based on two scores by definition (Griffin, Murray, \& Gonzalez, 1999). To facilitate the interpretation of the observed effects and disentangle the effects of responses toward tea and coffee pictures, we therefore inspected the predictive value of the single underlying scores in additional multiple regression analyses in a second step.

Predictive validity of differences in approach movement times. We expected that the differences in approach movement times toward coffee and tea pictures would predict 
implicit preferences for coffee compared to tea, as well as consumer choice, willingness to pay, and self-reported preferences. To test these predictions, we computed intercorrelations of differences in approach movement times and the mentioned variables. An overview of all intercorrelations is depicted in Table 1. In line with our hypotheses, differences in approach movement times correlated significantly with all dependent measures. The more quickly participants approached coffee pictures (compared to tea pictures), the more packages of coffee they chose, the more they were willing to pay for a cup of coffee compared to a cup of tea, the stronger were their reported preferences for coffee compared to tea, and the stronger were their implicit preferences for coffee compared to tea; all $r \mathrm{~s}$ were between .33 and $.39, p s$ $<.05$.

Predictive validity of differences in recognition times. First we tested whether there are substantial differences between recognition times of coffee pictures and recognition times of tea pictures. A t-Test for dependent samples indicated that the two recognition times did not differ, $t(38)=.65, p=.52$. For the predictive validity of the recognition time, we assumed no strong correlations with the dependent measures because the two categories were highly similar to each other and differed only moderately in positive valence. The correlations of the differences in recognition times of coffee and tea pictures with the dependent measures were all nonsignificant; all $r$ s were between -.23 and $.10, p s>.15$ (see Table 1 ).

\section{Incremental predictive validity of differences in approach movement times over}

other measures. In a first analysis, we tested the incremental validity of differences in approach movement times over differences in recognition times. We therefore computed multiple regression analyses for the prediction of each consumption measure with the differences in approach movement times and differences in recognition times as predictors. An overview of the regression results is depicted in Table 2. Congruent with our hypothesis, differences in approach movement times were significant predictors in all regression 
equations, $\beta \mathrm{s}>.34, t \mathrm{~s}>2.12, p \mathrm{~s}<.05$. By contrast, differences in recognition times were non-significant in all regression equations, $\beta \mathrm{s}<.18, t \mathrm{~s}<1.18, p \mathrm{~s}>.25$.

In a second analysis, we examined the incremental validity of the approach movement times compared to implicit preferences measured with the IAT. The IAT can be regarded as the standard measure to assess implicit preferences that has been frequently used in different areas of application (Greenwald et al., 2009). The IAT and the RaBAT approach movement difference score showed significant correlations to all dependent measures (Table 1). To test the incremental validity of the RaBAT compared to the IAT, we computed multiple regression analyses with the RaBAT approach movement difference score and the IAT as predictors. As dependent variables we entered consumer choice, willingness to pay, and selfreported preferences (see Table 3). When the IAT score and the RaBAT approach movement difference score were entered into the regression equation, the IAT score remained significant in predicting choice and self-reported preferences, $\beta \mathrm{s}>.38, t \mathrm{~s}>2.47, p \mathrm{~s}<.02$, while the IAT score did not remain significant in predicting willingness to pay, $\beta=.23, t=1.45, p=.16$. By contrast, the RaBAT approach movement difference score approached significance predicting willingness to pay, $\beta=.30, t=1.90, p=.065$, but did not reach conventional levels of significance predicting choice and self-reported preferences, $\beta \mathrm{s}<.22, t \mathrm{~s}<1.42, p \mathrm{~s}>.16$. A hierarchical regression analyses supports this finding. When adding the RaBAT approach movement difference score to the regression equation predicting choice and self-reported preferences the $R^{2}$ did not significantly increase when the IAT was already a predictor, $\Delta R^{2}<$ $.04, p s>.17$. When predicting willingness to pay, however, the change in $R^{2}$ approached significance when the RaBAT approach movement difference score was added to the regression equation, $\Delta R^{2}=.08, p=.065$. When the RaBAT approach movement difference score already was entered as a predictor, the IAT score significantly increased $R^{2}$ for choice and self-reported preferences, $\Delta R^{2}>.12, p s<.02$. But, when predicting willingness to pay, 
the IAT did not significantly increase $R^{2}$ when the RaBAT approach movement score already was a predictor, $\Delta R^{2}=.05, p=.16$. In this case, the RaBAT approach movement difference score, $\beta=.39, t=2.56, p=.015$, already led to a significant $R^{2}$ when being a single predictor, $R^{2}=.15, p=.015$.

Additional analyses. The reported analyses showed that approach movement times measured with the RaBAT predict consumer preferences, willingness to pay and consumer choice. However, these analyses were based on differences between the approach movement times toward tea and coffee pictures. As mentioned above, difference scores are ideal if choices between alternatives are of interest. Also, they help to reduce variance originated by influences such as individual differences in cognitive abilities. However, correlations based on difference scores allow only limited interpretations (Griffin et al., 1999). For example, individuals who equally like tea and coffee might approach and purchase tea as well as coffee during their weekly grocery shopping. However, such individuals show the same difference score as individuals who equally dislike tea and coffee. Hence, even if we recommend some kind of benchmark comparison and the respective difference score for practice, it is important to disentangle the difference scores to show that the single response times predict consumer behavior in the expected direction. Griffin et al. recommend the computation of multiple regressions with the underlying scores to facilitate the interpretation of correlations based on difference scores. In line with this recommendation, we computed multiple regression analyses that focus on the unique effects of approach movement times toward tea and coffee pictures. In these multiple regression analyses, we included the approach movement time toward tea pictures and the approach movement time toward coffee pictures as separate predictors. The dependent measures were the implicit preferences measured with the IAT, consumer choice, self-reported preferences for coffee, self-reported preferences for tea, willingness to pay for coffee, and willingness to pay for tea. Table 4 provides an overview of 
the results. The approach movement time toward coffee pictures was a negative predictor of the IAT, choice, preference for coffee, and willingness to pay for coffee, $\beta \mathrm{s}>.74, t \mathrm{~s}>1.79$, $p s<.10$. This means that as participants were faster to approach coffee they showed greater preference for coffee on the IAT and the choice measure, self-reported greater preferences for coffee and were willing to pay more for coffee. Interestingly, approach movement time toward coffee pictures was a positive predictor of one's explicitly reported preference for tea $(\beta=.86, t=2.06, p=.047)$, meaning, the faster one approached coffee, the less one reported liking tea. The approach movement time toward tea pictures was a predictor of the IAT, choice, preference for coffee $(\beta \mathrm{s}>.72, t \mathrm{~s}>1.73, p \mathrm{~s}<.10)$, and a negative predictor for preference for tea $(\beta=-.83, t=-1.99, p=.05)$. This indicates that the faster participants approached the tea pictures, the greater was their preference for tea on the IAT, the more likely they were willing to choose tea, the weaker was their explicit preference for coffee and the stronger was their explicit preference for tea. Hence, the pattern of correlations regarding the underlying approach movement times toward coffee and tea pictures are in line with the formulated expectations and support the interpretation of the difference scores. The sign of all regression coefficients was in the expected direction.

\section{Discussion}

The results of the Pilot Study showed that the RaBAT is able to tap behavioral approach tendencies toward distinctly positive and negative stimuli. The results of Study 1 extended this research to consumer contexts and were able to demonstrate the ability of the RaBAT to assess individual differences in behavioral approach tendencies toward consumption objects that varied on the positive end of the scale. Differences in approach movement times were correlated with choice, willingness to pay, self-reported preferences, and with the IAT, a measure of implicit preferences. Furthermore, the analyses indicated that the underlying single approach movement times can be used as predictors also. 
While Study 1 illustrated the validity of the RaBAT, it also demonstrated the strength of the IAT in predicting consumer preference and choice. The RaBAT approach movement score did not increase the prediction of consumer preferences and choice over the IAT. However, it is important to note that the correlation of the RaBAT scores with consumer preferences and choice were on a similar level as those for the IAT, and, even more importantly, the RaBAT approach movement scores showed incremental validity in predicting willingness to pay, which is one of the most important variables in the area of consumer research.

It is important to note that the results of Study 1 show that in consumer contexts, it is useful to assess approach movement time separately from recognition time, as recognition time was not correlated with any indicators of consumption. We assume that the differences in valence and accessibility of the stimuli used in Study 1 were not pronounced enough to produce meaningful differences in the recognition responses as were the stimuli we used in the Pilot Study. Still, it is notable that approach movement time was sensitive enough to detect these differences, which is in line with studies demonstrating that the compatibility of a measure and the relevant behavior is an important indicator to predict the behavior (Ajzen \& Fishbein, 1977; Zanna et al., 1980).

Given the first evidence for the differential predictive validity of approach movement and recognition times, it is now of interest to test conditions under which approach movement time would be better able to predict behavior than self-report. The aim of Study 2 was to test such conditions. Additionally, Study 2 was conducted to improve the procedure of the RaBAT. In the Pilot Study and in Study 1, the procedure rests on participants' compliance with the instruction. It is difficult to confidently conclude whether the participants moved their finger before they recognized the stimuli or not. In Study 2, we used an advanced version of the RaBAT to ensure participants' compliance with the instructions. 


\section{Study 2}

In Study 1, we provided the first evidence that the approach movement time measured with the RaBAT can predict consumer behavior. Differences in approach movement times toward coffee and tea correlated significantly with the choice between tea and coffee, drinking preferences for tea or coffee, and willingness to pay for tea or coffee. Thus, we can conclude that the RaBAT is a valid measure of consumer behavior. It is also less cumbersome and more easily applied than other behavioral approach-avoidance measures. No special apparatus is needed, and it is shorter than the IAT. However, if an easily applicable measure is sought, self-reports are probably the most convenient instruments, and the question remains whether the RaBAT provides any unique advantages over self-reports.

Taking this argument into consideration, it brings up the question of whether there is a context in which a behavioral approach measure would be more adequate than a self-report measure. Previous research has indicated that product choice is best predicted by attitudes when the attributes, which were salient at the time the attitude was measured, are salient in the choice situation as well (Shavitt \& Fazio, 1991). More specifically, Millar and Tesser (1986, 1992) assumed that behavior is driven either cognitively or affectively and they showed that attitudes that are measured under an affective or cognitive focus correlate with behavior when it is driven by the respective focus (cf. also Zanna \& Rempel, 1988). The RaBAT was developed to tap into impulsive processes underlying judgments and to reflect the spontaneous affective response. We therefore expected that the RaBAT would be able to explain additional variance in consumer behavior in comparison to self-report scales when the behavior is driven mainly by affective responses (Hypothesis 4). Other research has also shown that indirect response-time-based attitude measures are often better predictors of (consumer) behavior compared to self-reports when the behavior is affect-based or impulsive 
(e.g., Florack et al., 2010; for reviews, see Friese et al., 2009; Hofmann, Gawronski, Gschwendner, \& Schmitt, 2005; Hofmann, Gschwendner, et al., 2005).

To test our prediction, we applied the RaBAT and self-report scales to the assessment of attitudes toward fruit and chocolate, and then induced an affective or cognitive focus before participants finally chose between fruit or chocolate. As in Study 1, we expected that differences in approach movement times, but not in recognition times, would predict choice. Moreover, in line with previous studies that demonstrated the influence of impulses under an affective compared to a cognitive focus (e.g., Scarabis, Florack, \& Gosejohann, 2006; Smith \& Nosek, 2011), we hypothesized that approach movement times measured with the RaBAT would show a stronger unique contribution to the prediction of a choice between fruit and chocolate when individuals focused on their affect than when they thought about the reasons for their choice.

For further cross-validation, we also examined the correlations of the RaBAT approach movement times with another measure of automatic evaluations, namely, an affective priming task (Fazio et al., 1986; Fazio, Jackson, Dunton, \& Williams, 1995), which has also been frequently applied in consumer research (e.g., Berger, 1992; Spruyt et al., 2007; Yi, 1990).

\section{Method}

Design and participants. Forty-eight participants were recruited for a market research study and received 10 Swiss Francs (approximately $\$ 10$ US or $8 €$ ) or partial course credit in exchange for their participation. Participants selected for the study took part in the study between 9 am and $4 \mathrm{pm}$. They were randomly assigned to one of two conditions (affective focus vs. cognitive focus). Seven participants were dropped from the analyses because they did not follow the instructions (four participants used two instead of one finger while completing the RaBAT; one participant exceeded a set time limit for completion of the 
experiment) or indicated an aversion against the choice options (one participant indicated that she would under no circumstances eat the provided food options; one person indicated that she would not eat the food options, but would give it away). Thus, data from 41 participants ( 36 women and 5 men) were analyzed. The ages of participants ranged from 17 to 49 years with a mean age of $25.83(S D=8.08)$.

Procedure. Participants were tested in groups of up to three persons. After being greeted and seated at a table with a desktop computer, participants signed a statement of agreement and began the experiment on the computer. They first ran through the phases of the RaBAT (approximately 2 minutes) and then completed the affective priming task (approximately 6 minutes). Next, participants filled out a questionnaire concerning the tastiness of fruit and chocolate (approximately 2.5 minutes). After a filler task (approximately 13 minutes), half of the participants completed the affective focus manipulation and the other half the cognitive focus manipulation. Finally, the participants chose between fruit and chocolate and were debriefed and dismissed.

Materials and apparatus. For the RaBAT and the affective priming, we chose the same 20 pictures of fruits and chocolates. The 10 fruit pictures included five pictures of bananas and five pictures of apples. Chocolate pictures included 10 pictures of two different chocolate brands: five pictures of "Rittersport" and five pictures of "Milka". All pictures had a size of $250 \times 200$ pixels. We conducted the experiment on IBM-compatible ( $3000+$ processor) desktop computers with Windows XP as the system software. Participants viewed the screen from a distance of approximately $55 \mathrm{~cm}$ and provided responses on a Swiss keyboard.

Measures. Recognition and approach movement task. An advanced version of the RaBAT was programmed to ensure participants compliance to recognize the pictures. In detail, similar to a go/no-go association task (Nosek \& Banaji, 2001), we randomly included 
trials with distractor items to which participants were not allowed to react. Additionally, instead of pressing the index finger on the space bar while waiting for the presentation of a stimulus as in the Pilot Study and Study 1, participants in Study 2 just put a finger on the space bar, but did not press it until they recognized the presented picture. Participants were instructed to press the space bar as soon as they recognized the picture and then to strike the $\mathrm{Z}$ key as quickly as possible. Upon striking the $\mathrm{Z}$ key, the pictures were zoomed in on to illustrate the approach character of the movement, and participants again put their finger on the space bar. The practice phase contained 15 trials, in which participants were instructed to respond to rectangles and triangles, but not to circles. The main phases contained 20 trials, in which participants responded to the randomly selected fruit and chocolate pictures, but not to stars. During the entire task, participants received instantaneous accuracy feedback. The recognition time was defined as the duration of time between the presentation of a picture and the pressing of the space bar. The approach movement time was defined as the duration of time between pressing the space bar and pressing the $\mathrm{Z}$ key. The approach movement and recognition time scores were computed in the same way as in Study 1 , taking the mentioned differences into account.

Affective priming task. We adapted an affective priming task that was recently presented by Degner and Wentura (2010). As primes, we used the same fruit and chocolate pictures that we used for the RaBAT. The target set consisted of the same positive and negative pictures that we used in Study 1 for the IAT. The task included four blocks, each containing 40 trials. Each trial began with the presentation of the prime stimulus for $317 \mathrm{~ms}$, replaced by a blank screen. The target stimulus followed after $133 \mathrm{~ms}$ (stimulus onset asynchrony $[\mathrm{SOA}]=450 \mathrm{~ms}$ ). The intertrial interval was $1,000 \mathrm{~ms}$. Within a block, each prime was presented once in each target condition. To analyze the affective priming task, first, all response times were log-transformed. Then, individual affective priming scores were 
computed by subtracting the difference between the mean latency of fruit/negative trials and fruit/positive trials from the difference between the mean latency of chocolate/negative trials and chocolate/positive trials. Thus, positive affective priming scores indicate a preference for chocolate over fruit.

Tastiness rating (self-report). Participants were asked to indicate on a 9-point scale ranging from 1 (not at all) to 9 (very much) how much several adjectives applied to fruit or chocolate. Half of the items were positive (tasty, nutty, delicious, appetizing, healthy, wholesome, pleasant, natural), whereas the other half of the items were negative (repellent, unsavory, disgusting, unappetizing, unhealthy, harmful, unnatural, unwholesome). The averaged ratings of chocolate on the positive (Cronbach's $\alpha=.65$ ) and on the negative scales (Cronbach's $\alpha=.64$ ), as well as the ratings of fruit on the positive (Cronbach's $\alpha=.91$ ) and the negative scales (Cronbach's $\alpha=.72$ ) were combined into single scales for chocolate and for fruit. To build a relative measure for the self-reported tastiness rating, we computed the difference between the two scales such that high values indicate a preference for chocolate over fruit.

Induction of affective or cognitive focus and choice task. Before choosing a snack, participants were randomly assigned to one of two focus conditions. Participants in the affective focus condition imagined a situation in which they would really enjoy eating a bar of chocolate or fruit, and were asked to think about which of the two snacks would make their mouths water more. Furthermore, they were asked to close their eyes and to take a moment to imagine the taste of chocolate or fruit. Participants in the cognitive focus condition were also instructed to think about their preference for one of the snacks, but in contrast to the affective focus condition, they were asked to carefully analyze their reasons and to list at least five arguments concerning the snacks. The processing time for both conditions was limited to $90 \mathrm{~s}$. A similar manipulation was used already by Scarabis et al. (2006). After participants 
completed the manipulation, they chose between four snacks. The same snacks that we presented in the RaBAT and in the affective priming task (banana, apple, Rittersport chocolate bar, Milka chocolate bar) were arranged on a plate and covered by a lid. When the experimenter lifted the lid, participants were asked to grab one of the snacks. After participants left the lab, the experimenter recorded their choice.

\section{Results}

Preliminary analyses. We expected at least moderately positive correlations between the differences in approach movement times toward fruit and chocolate, the differences in tastiness ratings, and the affective priming scores because all three measures supposedly capture some aspects of preference. Table 5 shows the correlations between all variables that we considered to be predictors of choice. In line with our hypothesis, the differences in approach movement times were correlated with the affective priming scores, $r(41)=.27, p=$ .045 , one-tailed. The faster participants approached chocolate pictures (compared to fruit pictures), the more positive were their automatic evaluations of chocolate compared to fruit. All other correlations were nonsignificant; all $r \mathrm{~s}$ were between -.17 and $.09, p \mathrm{~s}>.28$, onetailed.

Choice task. To investigate our hypotheses, we ran multiple regression analyses. First, all continuous variables were z-standardized. The choice between chocolate and fruit served as the dependent measure $(1=$ fruit, 2 = chocolate $)$. To test whether the differences in approach movement times and the focus manipulation predicted choice, we entered as predictors the dummy-coded focus manipulation $(0=$ cognitive, $1=$ affective $)$, the difference in approach movement times, and the interaction between these variables. As expected, the interaction between the difference in approach movement times and the focus manipulation was significant, $\beta=.62, t=2.42, p=.02$. Simple slope tests revealed that in the affective focus condition, the difference in approach movement times predicted the choice very well, $\beta$ 
$=.52, t=2.04, p=.048$, whereas it had no impact on participants' decisions in the cognitive focus condition, $\beta=-.25, t=-1.30, p=.20$.

In a further multiple regression analysis, we tested whether the difference in recognition times predicted the choice. As predictors, we entered the dummy-coded focus manipulation $(0=$ cognitive, $1=$ affective $)$, the difference in recognition times, and the interaction between these variables. The interaction between the difference in recognition times and the focus manipulation was not significant, $\beta=-.31, t=-1.09, p=.28$. Also, the main effects for the difference in recognition times and the focus manipulation did not reach conventional levels of significance, $\beta \mathrm{s}<.28, t \mathrm{~s}<1.70, p \mathrm{~s}>.11$.

Incremental predictive validity of differences in approach movement times over other measures. To test whether the difference in approach movement times contributes to the prediction of choice independently from other measures, we computed a further multiple regression analysis. For the prediction of choice, we entered the difference in approach movement times, the affective priming score, the tastiness rating, the dummy-coded focus manipulation $(0=$ cognitive, $1=$ affective $)$, the interaction between the difference in approach movement times and the focus manipulation, the interaction between the affective priming score and the focus manipulation, as well as the interaction between the tastiness rating and the focus manipulation as predictors. An overview of the regression results is depicted in Table 6. In this equation, only the interaction between the difference in approach movement times and the focus manipulation was significant, $\beta=.53, t=2.48, p=.02$, indicating that under an affective focus, the RaBAT approach movement time is a better predictor of choice than automatic evaluations, measured with an affective priming paradigm, and explicit tastiness ratings. All main effects and all other interactions were not significant, $\beta \mathrm{s}<.30, t \mathrm{~s}<$ $1.61, p \mathrm{~s}>.12$.

\section{Discussion}


The results of Study 2 provide further support for the validity of the RaBAT by ensuring that participants complied with the instructions. We found that the difference in approach movement times was a better predictor of consumer choice when participants focused on their affect than when they thought about the reasons for their choice. By contrast, the differences in recognition times were in no condition correlated with choice. Thus, approach movement time, but not recognition time as measured with the RaBAT, tap into impulsive processes, which are known to affect behavior more under an affective than under a cognitive focus (Scarabis et al., 2006). Indeed, it cannot be expected that a measure of approach predispositions would predict behavior in every case, but, as a task to measure automatically activated approach tendencies, it should predict behavior that is driven mainly by impulses (Florack et al., 2010; Friese et al., 2008).

The reported correlation between the difference in approach movement times and an automatic evaluation measured with an affective priming paradigm provides further support for the validity of the RaBAT as a measure for capturing automatic approach responses. More importantly, the RaBAT has incremental validity compared to the affective priming measure and an explicit taste measure. The reported effects still remained significant when the affective priming score and an explicit tastiness rating were taken into account.

It is important to note that we applied an adapted version of the RaBAT in Study 2. In contrast to the previous studies, we included trials during which participants were not allowed to respond. This change helps to ensure that participants do not respond without recognizing the presented pictures. The results we obtained with the slight change in the method further strengthen the validity of the results of the Pilot Study and Study 1. We can now rule out that the low correlations between recognition times and consumer preferences and choice in Study 1 can be explained by the possibility that participants responded without recognition. Moreover, we can conclude from Study 1 that the simple instruction to respond to a picture 
when it is recognized is enough to make the following approach movements a meaningful predictor of consumer preferences and choice.

\section{General Discussion}

Although swift-selection platforms provide marketing researchers with a valuable insight into consumer behavior, they do not distinguish between speed of recognition and speed of movement. In this paper, we presented the RaBAT as an alternative to swiftselection platforms. The RaBAT is much easier to apply than classic swift-selection platforms, and delivers scores for the speed of recognition and the speed of approach movements. Applying the RaBAT, we showed that recognition and approach movement times were faster for positive than for negative stimuli. However, we found that when choice alternatives that differ less distinctly in valence were considered, approach movement time was a better predictor of consumer choice, willingness to pay, and self-reported preferences than recognition time. Moreover, when choice was made with an affective focus, approach movement time was a better predictor of consumer choice than self-report measures. Also, approach time, but not recognition time, correlated with two other measures of implicit preferences.

The finding of the Pilot Study that participants were faster at moving their finger to the target key on the keyboard when we presented positive stimuli than when we presented negative stimuli is important with respect to two aspects. First, the results provide the first evidence that the RaBAT is able to distinguish between positive and negative stimuli, and second, the results underline that the recorded movement can indeed be interpreted as an approach movement. This evidence is important because the results of previous studies have suggested that a movement away from oneself toward a stimulus reflects approach or avoidance tendencies dependent upon the context of the movement (Eder \& Rothermund, 2008; Seibt et al., 2008). Similar to other recently published procedures (e.g., van Dantzig et 
al., 2008), the RaBAT is constructed in such a way as to make the approach function of the movement clear by simulating the movement of the presented stimuli toward participants on a computer screen after participants reached the target key.

Study 1 provided the first evidence that approach movement times measured with the RaBAT can predict consumer behavior. Differences in approach movement times toward coffee and tea correlated significantly with choice, drinking preference, and willingness to pay. Interestingly, this correlation was not affected when we controlled for differences in recognition times. Thus, the consideration of approach movement time can be regarded as the central feature of the RaBAT, which has clear incremental validity when considered in addition to recognition responses. Indeed, recognition time reflected the differences between positive and negative stimuli in the Pilot Study, but did not correlate with individual differences in consumption preferences in Study 1, or with choice in Study 2 when the stimuli did not differ in valence. These results are in line with Unkelbach et al. (2008), who showed that recognition time differentiates between concepts that differ clearly in valence. However, when predicting consumer behavior for which differences in valence and density of the categories are less distinct, recognition time contributes to a lesser degree to the detection of these concepts than approach movement time. This result supports theories proposing an advantage of measures that are compatible with the predicted behavior (Ajzen \& Fishbein, 1977; Zanna et al., 1980). Indeed, the approach movement is a key part of the selection of a product in many contexts, while the recognition might lead to approach, no action, or avoidance. From a methodological perspective, we consider this to be particularly noteworthy because, to our knowledge, the RaBAT is the first measure to demonstrate the importance of separating recognition speed from approach movement time when predicting consumer behavior. Having shown that recognition time as such is not necessarily a good predictor, 
separating it from the measurement of approach should result in a reduction of noise and better predictions.

In Study 2, we slightly changed the procedure of the RaBAT to ensure that participants responded only after they had consciously recognized the stimuli. This change in the procedure was important, because it shows that participants do not only respond randomly to the stimuli and that it is not a random response that makes recognition times meaningless. The results of Study 2 support our assumption that in a condition where conscious recognition of stimuli is ensured approach movement times provide better predictions than recognition times.

Although this change in the procedure was important to stress the difference between approach and recognition, it does not mean that we assume that conscious processes like conscious recognition drives approach behavior. By contrast, we completely agree with the literature on affective primacy (e.g., Zajonc, 1984) and embodied cognition (Niedenthal, Barsalou, Winkielman, Krauth-Gruber, \& Ric, 2005; Niedenthal,Winkielman, Mondillon, \& Vermeulen, 2009) that embodied responses to stimuli like affect or movements often precede conscious processes. In line with this literature, we assume that already the incidental perception of a stimulus automatically activates a simulation of responses in all modalities that are usually involved in a response to this stimulus. If approach is an associated response, then individuals should be faster in responding with approach. In our task this response followed a conscious recognition. But it may also be likely that the subliminal presentation of stimuli facilitates approach movements to other stimuli - though this approach does not allow separating recognition from approach movement times as the RaBAT does.

The notion that the approach time of the RaBAT indeed taps into impulsive processes is supported by the findings of Study 2, because the approach movement times are more likely to predict choice behavior under conditions of an affective focus than when individuals think 
about the reasons for their choice. This finding is congruent with previous research that has shown that the automatic components of attitudes are more likely to shape behavior when individuals focus on their affective response to choice options than when they analyze the advantages or disadvantages of relevant options (Florack et al., 2010; Scarabis et al., 2006). Also, theoretical models on impulsive consumer behavior propose a strong relation between impulses of approach and avoidance with affect (Beatty \& Ferrell, 1998). In some ways, approach and avoidance tendencies can be seen as the behavioral part of an affective response. For example, a consumer may feel the affective response of being attracted by a product and may move toward this product. Deliberate thinking, by contrast, can weaken the influence of affective responses on choice options (cf. Shiv \& Fedorikhin, 1999).

More support for this reasoning comes from the correlations between the approach component of the RaBAT and other measures of implicit preferences. In Study 1, the RaBAT correlated with the IAT (Greenwald et al., 1998), and in Study 2, with an affective priming task (Fazio et al., 1986). Both the IAT and affective priming can be regarded as the standard measures for assessing processes of implicit preferences that have been applied in many studies of consumer research (e.g., Greenwald et al., 2009; Spruyt et al., 2007). However, we do not think that the RaBAT is completely congruent with these measures. We propose that the RaBAT provides an advantage in contexts in which researchers are interested in literal approach behavior, for example, when studying consumption behavior in a shopping context (e.g., effects of promotions). Indeed, we took great care in constructing a task that has a high conceptual overlap with the behavior of reaching for a product at the point of purchase. This is important because research has repeatedly shown that measures that are more compatible with behavior have a higher predictive validity for the behavior (Ajzen \& Fishbein, 1977; Zanna et al., 1980). Taking into account that the measured approach movement times predicted participants' actual product grasping in Study 2, we think that the approach 
movement times measured with the RaBAT reflect such applied approach movements very well.

Beside the high overlap with actual grasping movements and the separation of recognition and approach movement, another advantage of the RaBAT over the IAT and similar measures is based on the fact that the RaBAT is not limited to two categories, but can help in the study of responses to many groups and subgroups of items. Also, criticism that has been repeatedly formulated with regard to double categorization tasks such as the IAT does not apply to the RaBAT. For example, some authors have argued that participants might use concepts unrelated to attitudes or preferences to simplify the completion of the IAT (e.g., Fiedler et al., 2006; Rothermund \& Wentura, 2004). Since the RaBAT requires only the recognition of each stimulus and this recognition is separated from the approach movement, this is unlikely to affect the RaBAT scores.

A further advantage of the RaBAT concerns its simplicity and quick application. Whereas other measures such as the IAT or affective priming paradigms need approximately 6 minutes, the RaBAT can be applied within 2 minutes. In addition, the version of the RaBAT we presented here required only 15 practice trials and 20 test trials. Hence, the method is also shorter than the brief form of the IAT in which each of several blocks is comprised of 32 trials in its standard form (Sriram \& Greenwald, 2009). Furthermore, the RaBAT is more easily applied than other approach-avoidance measures because it does not need a joystick, a touch screen, or other complex apparatuses. This advantage allows for research to be conducted on the web, which is especially beneficial when many participants need to be obtained in a short period of time.

The usefulness of the RaBAT approach movement score is also evident if we regard that the RaBAT approach movement score predicted consumer choice in Study 2 beyond the affective priming measure. However, we have to acknowledge the strength of the IAT in 
predicting consumer preference and choice in Study 1. In this study, the RaBAT provided comparable predictions as the IAT, but did not add incremental predictive value compared to the IAT in the prediction of consumer preference and choice. But one finding in Study 1 also signals that the RaBAT is a valuable alternative to the IAT. The RaBAT was a superior predictor of the willingness to pay compared to the IAT. This finding is important, because willingness to pay is one of the most important variables in consumer research.

Besides the advantages of the RaBAT, also limitations have to be noted. Even if there is no systematic test of context effects on the RaBAT available so far, we would strongly recommend using the RaBAT as a measure not preceded by another measure. We have run the RaBAT in different conditions, and found the best predictive validity when the RaBAT is not preceded by any kind of other measures as reported in the current paper. Indeed, we would speculate that the RaBAT is sensitive for effects of previous experiences and behaviors. Future research should systematically assess the sensitivity of the RaBAT for such context effects and also effects of learning through previous experiences (e.g., conditioning).

\section{Conclusion}

In this paper, we introduced a new task to measure the speed of recognition and behavioral approach movements and demonstrated the importance of assessing recognition time separately from approach movement time. Whereas recognition time as well as approach movement time as measured with the RaBAT differed for positive and negative objects, only approach movement time predicted consumer preferences and behavior. Because an important feature of the RaBAT is that it is brief and easy to be applied, it might be a valuable alternative to swift-selection platforms and other more time-consuming methods for measuring behavioral approach predispositions. 


\section{References}

Abratt, R., \& Goodey, S. D. (1990). Unplanned buying and in-store stimuli in supermarkets. Managerial and Decision Economics, 11, 111-121.

Ajzen, I., \& Fishbein, M. (1977). Attitude-behavior relations: A theoretical analysis and review of empirical research. Psychological Bulletin, 84, 888-918.

Bargh, J. A., Chaiken, S., Govender, R., \& Pratto, F. (1992). The generality of the automatic attitude activation effect. Journal of Personality and Social Psychology, 62, 893-912.

Bamford, S., \& Ward, R. (2008). Predispositions to approach and avoid are contextually sensitive and goal dependent. Emotion, 8, 174-183.

Beatty, S. E., \& Ferrell, E., M. (1998). Impulse buying: Modeling its precursors. Journal of Retailing, 74, 169-191.

Berger, I. E. (1992). The nature of attitude accessibility and attitude confidence: A triangulated experiment. Journal of Consumer Psychology, 1, 103-123.

Brendl, C. M., Markman, A. B., \& Messner, C. (2005). Indirectly measuring evaluations of several attitude objects in relation to a neutral reference point. Journal of Experimental Social Psychology, 41, 346-368.

Brunel, F. F., Tietje, B. C., \& Greenwald, A. G. (2004). Is the Implicit Association Test a valid and valuable measure of implicit consumer social cognition? Journal of Consumer Psychology, 14, 385-404.

Chen, M., \& Bargh, J. A. (1999). Consequences of automatic evaluation: Immediate behavioral predispositions to approach or avoid the stimulus. Personality and Social Psychology Bulletin, 25, 215-224.

Degner, J., \& Wentura, D. (2010). Automatic prejudice in childhood and early adolescence. Journal of Personality and Social Psychology, 98, 356-374. 
De Houwer, J., (2003). The Extrinsic Affective Simon Task. Experimental Psychology, 50, 77-85.

De Houwer, J., Crombez, G., Baeyens, F., \& Hermans, D. (2001). On the generality of the affective Simon effect. Cognition and Emotion, 15, 189-206.

Dimofte, C. V. (2010). Implicit measures of consumer cognition: A review. Psychology \& Marketing, 27, 921-937.

Dimofte, C. V., \& Johansson, J. K. (2009). Scale-dependent automatic shifts in brand evaluation standards. Journal of Consumer Psychology, 19, 158-170.

Dimofte, C. V., \& Yalch, R. F. (2007). The SMAART scale: A measure of individuals' automatic access to secondary meanings in polysemous statements. Journal of Consumer Psychology, 17, 49-58.

Eder, A. B., \& Rothermund, K. (2008). When do motor behaviors (mis)match affective stimuli? An evaluative coding view of approach and avoidance reactions. Journal of Experimental Psychology, 137, 262-281.

Fazio, R. H. (1990). A practical guide to the use of response latency in social psychological research. In C. Hendrick, \& M. S. Clark (Eds.), Research methods in personality and social research (pp. 74-97). Newbury Park, CA: Sage.

Fazio, R. H., Jackson, J. R., Dunton, B. C., \& Williams, C. J. (1995). Variability in automatic activation as an unobtrusive measure of racial attitudes: A bona fide pipeline? Journal of Personality and Social Psychology, 69, 1013-1027.

Fazio, R. H., Powell, M. C., \& Williams, C. J. (1989). The role of attitude accessibility in the attitude-to-behavior process. Journal of Consumer Research, 16, 280-288.

Fazio, R. H., Sanbonmatsu, D. M., Powell, M. C., \& Kardes, F. R. (1986). On the automatic activation of attitudes. Journal of Personality and Social Psychology, 50, 229-238. 
Fiedler, K., Messner, C., \& Bluemke, M. (2006). Unresolved problems with the I, the A, and the T: A logical and psychometric critique of the Implicit Association Test (IAT). European Review of Social Psychology, 17, 74-147.

Florack, A., Friese, M., \& Scarabis, M. (2010). Regulatory focus and reliance on implicit preferences in consumption contexts. Journal of Consumer Psychology, 20, 193-204.

Friese, M., Hofmann, W., \& Wänke, M. (2008). When impulses take over: Moderated predictive validity of explicit and implicit attitude measures in predicting food choice and consumption behaviour. British Journal of Social Psychology, 47, 397-419.

Friese, M., Hofmann, W., \& Wänke, M. (2009). The impulsive consumer: Predicting consumer behavior with implicit reaction time measures. In M. Wänke, (Ed.), Social psychology of consumer behavior (pp. 335-364). New York: Psychology Press.

Friese, M., Wänke, M., \& Plessner, H. (2006). Implicit consumer preferences and their influence on product choice. Psychology \& Marketing, 23, 727-740.

Greenwald, A. G., McGhee, D. E., \& Schwartz, J. L. K. (1998). Measuring individual differences in implicit cognition: The Implicit Association Test. Journal of Personality and Social Psychology, 74, 1464-1480.

Greenwald, A. G., Nosek, B. A., \& Banaji, M. R. (2003). Understanding and using the Implicit Association Test: I. An improved scoring algorithm. Journal of Personality and Social Psychology, 85, 197-216.

Greenwald, A. G., Poehlman, T. A., Uhlmann, E., \& Banaji, M. R. (2009). Understanding and using the Implicit Association Test: III. Meta-analysis of predictive validity. Journal of Personality and Social Psychology, 97, 17-41.

Griffin, D., Murray, S., \& Gonzalez, R. (1999). Difference score correlations in relationship research: A conceptual primer. Personal Relationships, 6, 505-518. 
Gutjahr, G. (1974). Markt- und Werbepsychologie Teil 2 [Market and advertising psychology, part 2]. Heidelberg, Germany: I. H. Sauer-Verlag.

Hofmann, W., Friese, M., \& Gschwendner, T. (2009). Men on the "pull". Automatic approach-avoidance tendencies and sexual interest behavior. Social Psychology, 40, 73-78.

Hofmann, W., Gawronski, B., Gschwendner, T., Le, H., \& Schmitt, M. (2005). A metaanalysis on the correlation between the implicit association test and explicit self-report measures. Personality and Social Psychological Bulletin, 31, 1369-1385.

Hofmann, W., Gschwendner, T., Nosek, B. A., \& Schmitt, M. (2005). What moderates implicit - explicit consistency? European Review of Social Psychology, 16, 335-390.

Hofsten, C. V., \& Rönnqvist, L. (1988). Preparation for grasping an object: A developmental study. Journal of Experimental Psychology: Human Perception \& Performance, 14, $610-621$.

Horcajo, J., Briñol, P., \& Petty, R. E. (2010). Consumer persuasion: Indirect change and implicit balance. Psychology \& Marketing, 27, 938-963.

Hoyer, W. D. (1984). An examination of consumer decision making for a common repeat purchase product. Journal of Consumer Research, 11, 822-829.

Jaspert, F. (1963). Methoden zur Erforschung der Werbewirkung [Methods to measure advertising effects]. Stuttgart, Germany: C. E. Poeschel Verlag.

Krieglmeyer, R., \& Deutsch, R. (2010). Comparing measures of approach-avoidance behaviour: The manikin task vs. two versions of the joystick task. Cognition \& Emotion, 24, 810-828.

Lang, P. J., Bradley, M. M., \& Cuthbert, B. N. (2005). International affective picture system (IAPS): Affective ratings of pictures and instruction manual. Gainesville: University of Florida. 
Maison, D., Greenwald, A. G., \& Bruin, R. H. (2004). Predictive validity of the Implicit Association Test in studies of brands, consumer attitudes, and behavior. Journal of Consumer Psychology, 14, 405-415.

Millar, M. G., \& Tesser, A. (1986). Effects of affective and cognitive focus on the attitudebehavior relation. Journal of Personality \& Social Psychology, 51, 270- 276.

Millar. M. G., \& Tesser, A. (1992). The role of beliefs and feelings in guiding behavior: The mismatch model. In L. Martin \& A. Tesser (Eds.). The construction of Social Judgments (pp. 277-300). Hillsdale: Lawrence Erlbaum.

Morange, F., \& Bloch, H. (1996). Lateralization of the approach movement and the prehension movement in infants from 4 to 7 months. Early Development and Parenting, 5, 81-92.

Niedenthal, P. M., Barsalou, L. W., Winkielman, P., Krauth-Gruber, S., \& Ric, F. (2005). Embodiment in attitudes, social perception, and emotion. Personality and Social Psychology Review, 9, 184-211.

Niedenthal, P. M., Winkielman, P., Mondillon, L., \& Vermeulen, N. (2009). Embodiment of emotion concepts. Journal of Personality and Social Psychology, 96, 1120-1136.

Nosek, B. A., \& Banaji, M. R. (2001). The go/no-go association task. Social Cognition, 19, 161-176.

Puri, R. (1996). Measuring and modifying consumer impulsiveness: A cost-benefit accessibility framework. Journal of Consumer Psychology, 5, 87-113.

Rothermund, K., \& Wentura, D. (2004). Underlying processes in the implicit association test: dissociating salience from associations. Journal of Experimental Psychology: General, $133,139-165$.

Salcher, E. F. (1995). Psychologische Markenführung [Psychological brand management]. Berlin, Germany: de Gruyter. 
Scarabis, M., Florack, A., \& Gosejohann, S. (2006). When consumers follow their feelings:

The impact of affective or cognitive focus on the basis of consumers' choice.

Psychology \& Marketing, 23, 1015-1034.

Seibt, B., Neumann, R., Nussinson, R., \& Strack, F. (2008). Movement direction or change in distance? Self- and object-related approach-avoidance motions. Journal of Experimental Social Psychology, 44, 713-720.

Shavitt, S., \& Fazio, R. H. (1991). Effects of attribute salience on the consistency between attitudes and behavior predictions. Personality and Social Psychology Bulletin, 17, $507-516$.

Shiv, B., \& Fedorikhin, A. (1999). Heart and mind in conflict: The interplay of affect and cognition in consumer decision making. Journal of Consumer Research, 26, 278-292.

Smith, C. T., \& Nosek, B. A. (2011). Affective focus increases the concordance between implicit and explicit attitudes. Social Psychology, 42, 300-313.

Solarz, A. (1960). Latency of instrumental responses as a function of compatibility with the meaning of eliciting verbal signs. Journal of Experimental Psychology, 59, 239-245.

Spiegel, B. (1970). Werbepsychologische Untersuchungsmethoden. [Research methods in advertising psychology] Berlin, Germany: Duncker \& Humblot.

Spruyt, A., Hermans, D., De Houwer, D., Vandekerckhove, J., \& Eelen, P. (2007). On the predictive validity of indirect attitude measures: Prediction of consumer choice behavior on the basis of affective priming in the picture-picture naming task. Journal of Experimental Social Psychology, 43, 599-610.

Sriram, N., \& Greenwald, A. G. (2009). The brief implicit association test. Experimental Psychology, 56, 283-294.

Strack, F., Werth, L., \& Deutsch, R. (2006). Reflective and impulsive determinants of consumer behavior. Journal of Consumer Psychology, 16, 205-216. 
Unkelbach, C., Fiedler, K., Bayer, M., Stegmüller, M., \& Danner, D. (2008). Why positive information is processed faster: The density hypothesis. Journal of Personality and Social Psychology, 95, 36-49.

Van Dantzig, S., Pecher, D., \& Zwaan, R. A. (2008). Approach and avoidance as action effects. Quarterly Journal of Experimental Psychology, 61, 1298-1306.

Yi, Y. (1990). Cognitive and affective priming effects of the context for print advertisements. Journal of Advertising, 19, 40-48.

Zajonc, R. B. (1984). On the primacy of affect. American Psychologist, 39, 117-123.

Zanna, M. P., Olson, J. M., \& Fazio, R. H. (1980). Attitude-behavior consistency: An individual difference perspective. Journal of Personality and Social Psychology, 38, $432-440$.

Zanna, M. P., \& Rempel, J. K. (1988). A new look at an old concept. In D. Bar-Tal \& A. W. Kruglanski (Eds.), The Social Psychology of Knowledge (pp. 315-334). Cambridge: Cambridge University Press. 


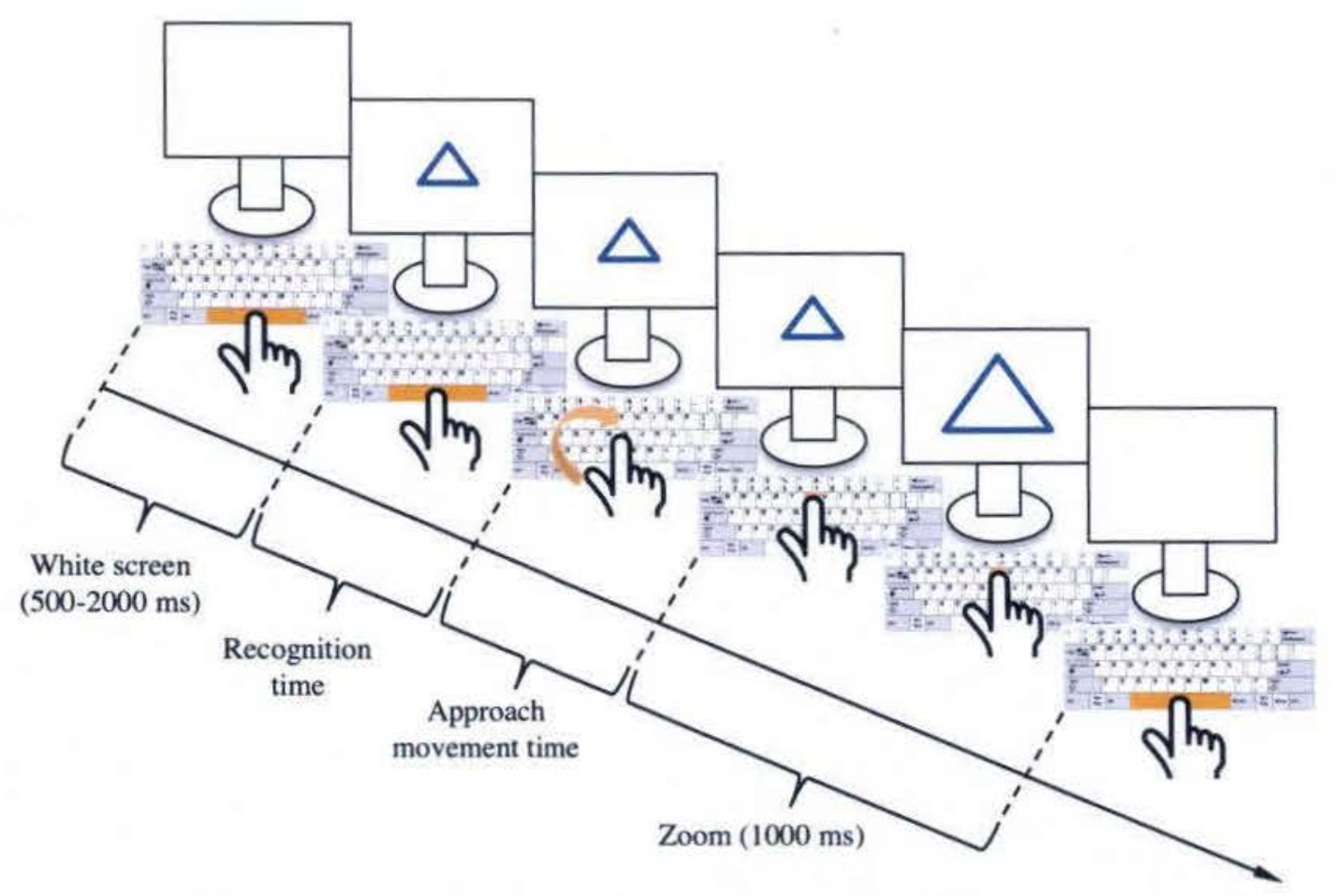

Figure 1. Schematic description and illustration of events during one response trial of the RaBAT. 


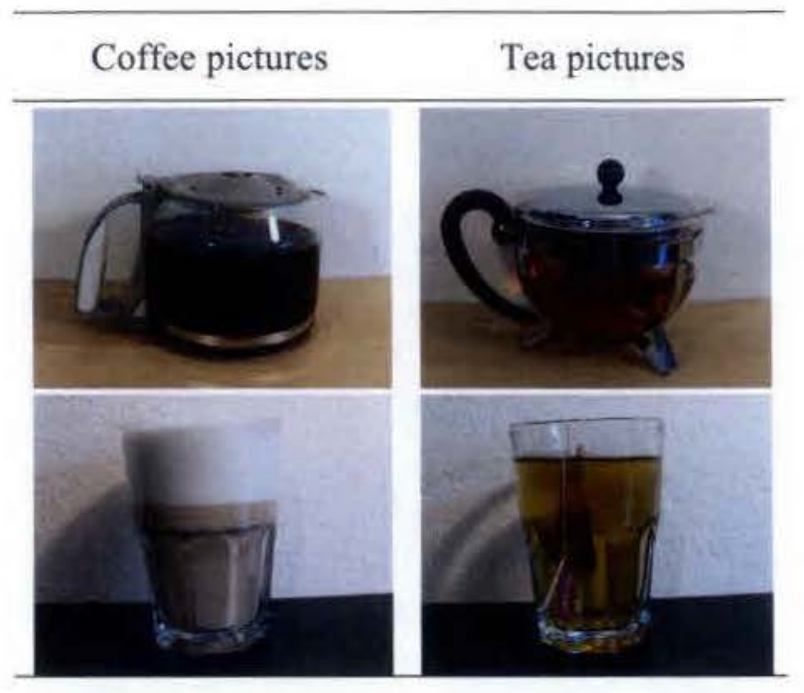

Figure 2. Sample stimuli of coffee and tea used in Study 1. 
Table 1

Intercorrelations for RaBAT Difference Scores and all Dependent Measures (Study 1). High Values Indicate a Favorable Response Toward Coffee Compared to Tea.

\begin{tabular}{|c|c|c|c|c|c|c|}
\hline & 1. & 2. & 3. & 4. & 5. & 6. \\
\hline 1. Approach movement & - & -.14 & $.36^{*}$ & $.36^{*}$ & $.39^{*}$ & $.33^{*}$ \\
\hline 2. Recognition & & - & -.14 & .10 & -.23 & .01 \\
\hline 3. IAT & & & - & $.46^{* *}$ & $.34^{*}$ & $.48 * *$ \\
\hline 4. Choice & & & & - & $.45^{* *}$ & $.91^{* * *}$ \\
\hline 5. Willingness to pay & & & & & - & $.44^{* *}$ \\
\hline 6. Self-reported preference & & & & & & - \\
\hline
\end{tabular}


Table 2

Standardized Multiple Regression Coefficients of Differences in Approach Movement Times and Differences in Recognition Times Predicting IAT, Choice, Willingness to Pay, and SelfReported Preferences (Study 1). High Values Indicate a Favorable Response Toward Coffee Compared to Tea.

\begin{tabular}{lcccc}
\hline & IAT & Choice & $\begin{array}{c}\text { Willingness to } \\
\text { pay }\end{array}$ & $\begin{array}{c}\text { Self-reported } \\
\text { preferences }\end{array}$ \\
\hline $\begin{array}{l}\text { Approach } \\
\text { movement }\end{array}$ & $.34^{*}$ & $.38^{*}$ & $.36^{*}$ & $.34^{*}$ \\
Recognition & -.10 & .15 & -.18 & .06 \\
\hline
\end{tabular}

${ }^{*} p<.05$. 
Table 3

Standardized Multiple Regression Coefficients of Differences in Approach Movement Times and the IAT Predicting Choice, Willingness to Pay, and Self-Reported Preferences (Study I). High Values Indicate a Favorable Response Toward Coffee Compared to Tea.

\begin{tabular}{lccc}
\hline & Choice & $\begin{array}{c}\text { Willingness to } \\
\text { pay }\end{array}$ & $\begin{array}{c}\text { Self-reported } \\
\text { preferences }\end{array}$ \\
\hline $\begin{array}{l}\text { Approach } \\
\text { movement }\end{array}$ & .22 & $.30^{+}$ & .18 \\
IAT & $.38^{*}$ & .23 & $.42^{* *}$ \\
\hline
\end{tabular}

${ }^{+} p<.07 ;{ }^{*} p<.05 ; * * p<.01$. 
Table 4

Standardized Multiple Regression Coefficients of Approach Movement Times Towards Tea

Pictures and Toward Coffee Pictures Predicting IAT, Choice, Self-Reported Preferences of

Coffee, Self-Reported Preferences of Tea, Willingness to Pay (WTP) for Coffee, and

Willingness to Pay (WTP) for Tea (Study 1). Small Approach Movement Scores Represent a

Fast Movement Toward the Target Object.

\begin{tabular}{lcccccc}
\hline & IAT & Choice & $\begin{array}{c}\text { Preference } \\
\text { for coffee }\end{array}$ & $\begin{array}{c}\text { Preference } \\
\text { for tea }\end{array}$ & $\begin{array}{c}\text { WTP for } \\
\text { coffee }\end{array}$ & $\begin{array}{c}\text { WTP for } \\
\text { tea }\end{array}$ \\
\hline $\begin{array}{l}\text { Approach movement } \\
\text { toward coffee }\end{array}$ & $-.88^{*}$ & $-.90^{*}$ & $-.87^{*}$ & $.86^{*}$ & $-.74^{+}$ & .49 \\
$\begin{array}{l}\text { Approach movement } \\
\text { toward tea }\end{array}$ & $.98^{*}$ & $.94^{*}$ & $.72^{+}$ & $-.83^{*}$ & .46 & -.51 \\
\hline
\end{tabular}

${ }^{+} p<.10 ; * p \leq .05$ (two-tailed). 
Table 5

Intercorrelations for RaBAT Difference Scores and all Independent Measures (Study 2).

\begin{tabular}{lcccc}
\hline & 1. & 2. & 3. & 4. \\
\hline 1. Approach movement & - & -.17 & $.27^{*}$ & .07 \\
2. Recognition & - & .04 & .09 \\
3. Affective priming score & & & - & -.07 \\
4. Tastiness rating & & & \\
\hline
\end{tabular}

${ }^{*} p<.05$ (one-tailed). 
Table 6

Standardized Logistic Regression Analysis for the Prediction of Choice (Study 2).

\begin{tabular}{lccc}
\hline Predictor & $\beta$ & $t$ & $p$ \\
\hline Approach movement $\left(\mathrm{X}_{1}\right)$ & -.30 & -1.61 & .12 \\
Affective priming score $\left(\mathrm{X}_{2}\right)$ & .21 & 1.07 & .29 \\
Tastiness rating $\left(\mathrm{X}_{3}\right)$ & .24 & 1.22 & .23 \\
Focus manipulation $\left(\mathrm{X}_{4}\right)$ & .02 & .13 & .90 \\
$\mathrm{X}_{1} \cdot \mathrm{X}_{4}$ & .53 & 2.48 & .02 \\
$\mathrm{X}_{2} \cdot \mathrm{X}_{4}$ & & & \\
&. .29 & -1.32 & .20 \\
$\mathrm{X}_{3} \cdot \mathrm{X}_{4}$ & & & .34 \\
\hline
\end{tabular}

